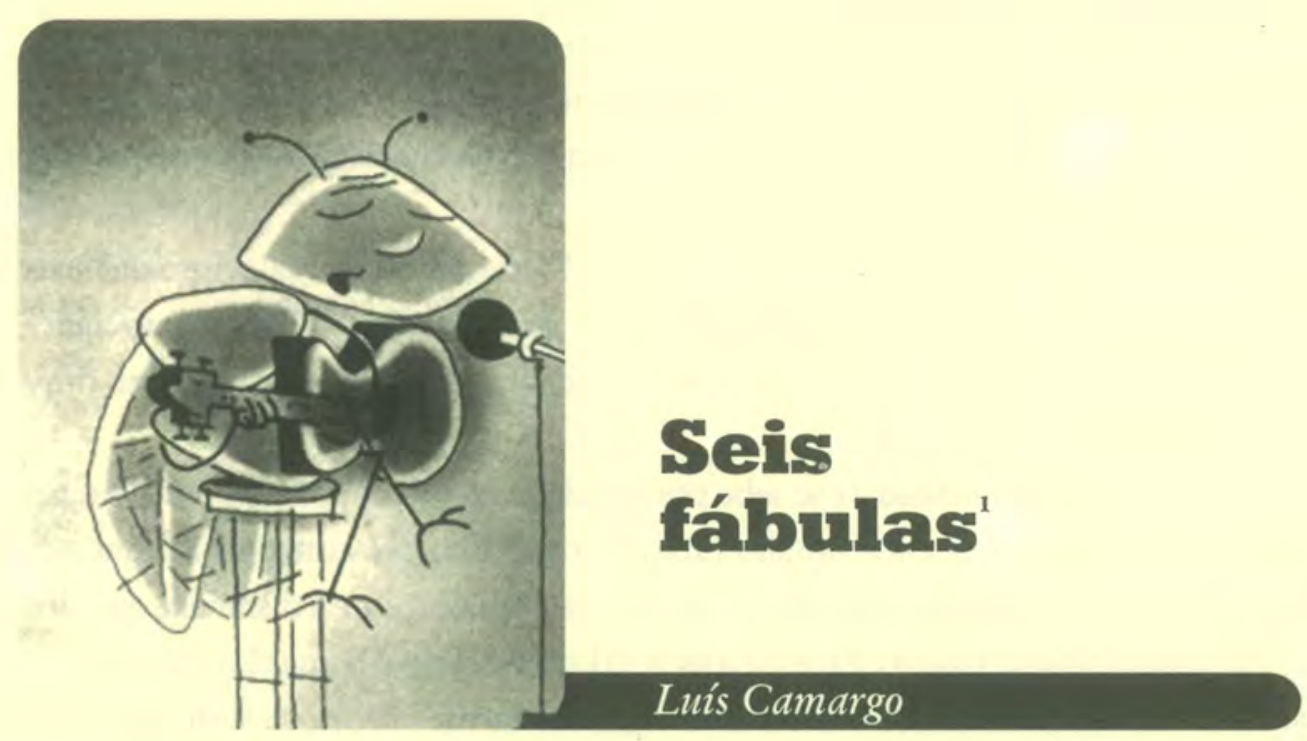

\title{
ESTAS FÁBULAS
}

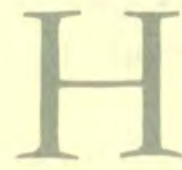
ace algunos años encontré en un libro didáctico de lengua portuguesa, la fábula La cigarra y la hormiga, de La Fontaine, junto a una ilustración que me llamó la atención: una cigarra estaba sentada en un banquito, con una guitarra, con los ojos cerrados, como si estuviera cantando para sí misma. Interpreté estas referencias como alusiones al cantautor João Gilberto y a la bossa nova. Por un lado, el texto era una traducción del francés al portugués; por el otro, la ilustración parecía haber traducido la fábula para el universo cultural brasileño.

Durante la maestría, estudié la poesía infantil de Cecília Meireles. Para el «Panorama de Poesía y Crónica» de la Fundación «Itaú Culturab», había investigado varios autores de poesía infantil. Me llamó la atención el gran número de poemas sobre animales. Marisa Lajolo, mi asesora de tesis, creyó que esto tenía algo que ver con las fábulas. Procuré,entonces, vencer un antiguo prejuicio contra las fábulas y comencé a leer y estudiar esta rica tradición.

\footnotetext{
'Traducción de Biagio D'Angelo.
} 
Como editor, participé de la edición de una colección de libros didácticos en lengua portuguesa. Había muchos fragmentos y pocos textos enteros, algunas viñetas, o estribillos, o un baiku, a lo mejor. ¿Por qué no incluir algunas fábulas? Acabé escribiendo algunas adaptaciones.

Siguiendo la lección de Monteiro Lobato, que ya había retomado esta tradición para el universo cultural brasileño al que me referí al inicio, comencé a sustituir animales europeos por brasileños, a incluir referencias paisajistas, en fin, a buscar el color local.

En el proceso creativo, se sabe por donde se comienza, pero es difícil prever el resultado. Algunas de estas fábulas fueron escritas directamente para alumnos de colegio de primaria, para un proyecto de lectura que coordino, a distancia, con dos profesoras de Río de Janeiro. En estos casos, el lector-objetivo limita el vocabulario, la sintaxis, la intertextualidad, etc. Sin embargo, sin darme cuenta, se sumaron otros intereses, otras referencias. Y las fábulas se posesionaron del género infantil.

La invitación de Biagio para publicar algunos textos creativos me tomó de sorpresa pues, empeñado con el doctorado, que concluí en febrero de este año, ya hace bastantes años que me dedicaba solo a los géneros académicos. La escritura de estas fábulas flagra, justamente, el regreso a mi escritura ficcional y poética. Todavía no he tenido el tiempo de reunirlas, seleccionarlas y publicarlas en portugués, iy ellas ya están apareciendo en español!

Mi gran agradecimiento para Biagio, que supo captar el espíritu juguetón de estas fábulas y acabó, también, por entrar en el juego haciendo algunas traducciones que son realmente recreaciones para el universo cultural peruano. 


\section{LA MAZA FUERTE DE LA JUSTICIA ${ }^{2}$}

La escena transcurre en Brasilia, la capital de Brasil.

La profesora lleva a los alumnos a pasear por la Plaza de los Tres Poderes. Muestra el Palacio de Justicia, el Supremo Tribunal Federal, como en la Plaza Grau de Lima:

Esta es la escultura Justicia, de Alfredo Ceschiatti.

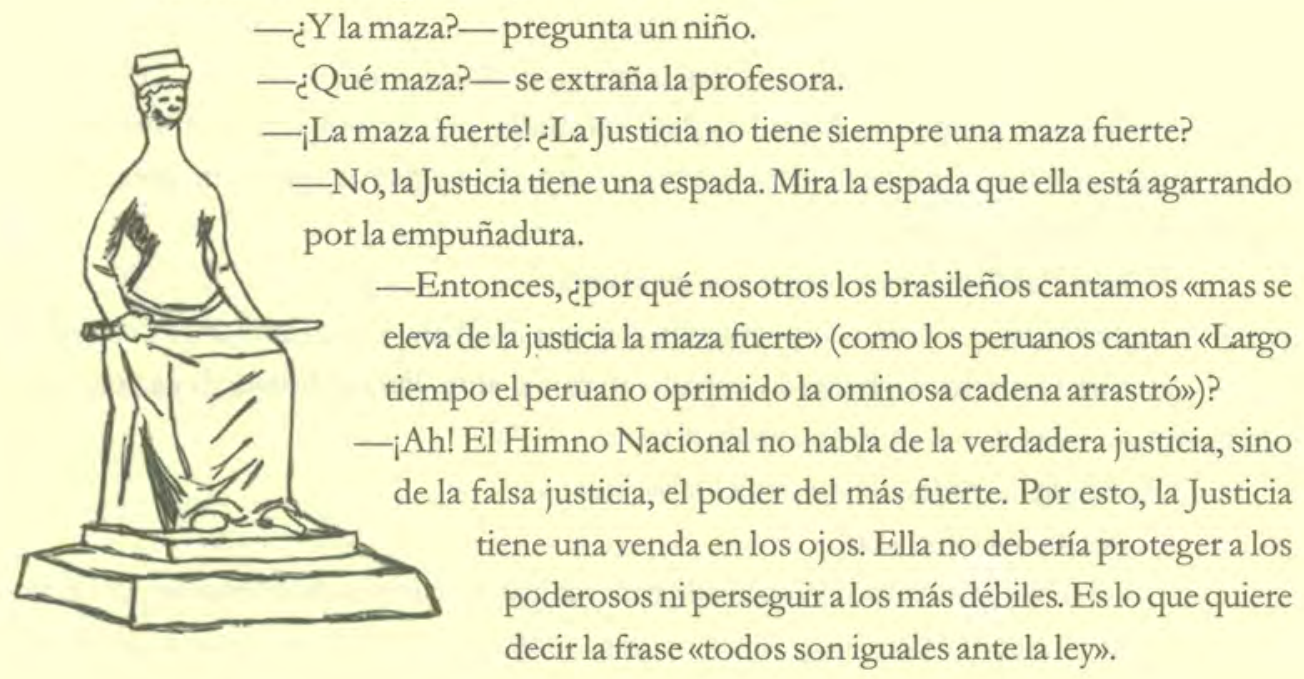

A este punto, Malapulga, un bello caballo, marcha, trota y galopa.

Con sed, va a beber agua en el lago Paranoá, cerca de la ciudad.

Un anta se asusta con el ruido y se esconde en el lago.

Malapulga se enardeció:

-Burro gordito, ¿por qué estás ensuciando mi agua?

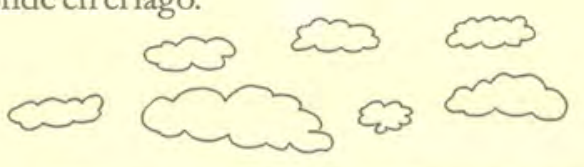

-Vuestra Equinencia me disculpe - dice el anta - pero este agua es del lago, el lago es de este ecosistema, este ecosistema es de la naturaleza, la naturaleza es nuestra casa. El agua no es solo vuestra, es de todos.

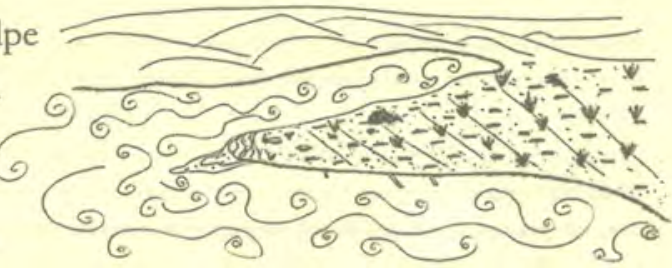

\footnotetext{
${ }^{2}$ A CLAVA FORTE DA JUSTIÇA: A cena se passa em Brasília. A professora leva os alunos para pașsear pela Praça dos Três Poderes. Mostra o palácio da justiça, o Supremo Tribunal Federal: -Esta é a escultura Justiça, de Alfredo Ceschiatti. -E a clava? - pergunta um menino. - Que clava? - estranha a professora. - A clava forte! A Justiça não tem uma clava forte?
} 
YVuestra Equinencia y yo también somos parte de la naturaleza, nuestra madre gentil.

Malapulga bufa, da patadas:

- ¡El agua es mía!

— ¿Vuestra Equinencia tiene negocio, contrato de alquiler, contrato de comodato, delocación?

—Ah!, ¿así es? Pues si alzas de la justicia la maza fuerte, jverás que yo no huyo de la lucha!

-Entonces es mejor, Vuestra Equinencia, reclamar al juez.

Malapulga, sin mucha paciencia para el estudio, no era muy fuerte en ortografía. Ve un turista con un polo que llevaba escrito pineapple juice y piensa que es un juez... Ve el diseño de una piña estampada y dice:

-Juez Piña, tengo una causa contra el anta.

El turista, que no entiende portugués, cree que el caballo lo está invitando a cabalgar.

El turista monta. Caballero y caballo atacan al anta. Para el turista, la caza es solo una diversión. Alza la maza fuerte y abate al tapir.

Malapulga agradece la ayuda del falso juez.

El turista (en su lengua):

- Caballito, jes mucha hospitalidad proporcionarme tamaño entretenimiento! Como dice el pueblo: quien no tiene can, caza con gato; quien no tiene moto, monta a caballo. Para demostrar mi gratitud, te daré silla, estribo, arreo, freno y un nombre: Malaleche.

-iQué burro que fui! — dice el caballo- para cobrar una pequeña deuda, jconseguí solo perjudicarme! De Malapulga terminé por ser Malaleche y di el adiós a mi libertad...

-Não, a Justiça tem uma espada. Olha a espada que ela está segurando no colo. -Então, por que a gente canta «mas se ergues da justiça a clava fortes? - Ah! O Hino Nacional não fala da verdadeira justiça, mas da falsa justiça, o poder do mais forte. Por isso a Justiça tem uma venda nos olhos. Ela não deveria proteger os poderosos nem perseguir os mais fracos. É o que quer dizer a frase «todos são iguais perante a lei». Nisso, Pavio Curto, um belo cavalo, marcha, trota e galopa. Com sede, vai beber água no lago Paranoá. Uma anta se assusta com o barulho e se esconde no lago. Pavio Curto se inflama: -Sua besta, por que está sujando a minha água? - Vossa eqüinência me desculpe — diz a anta-, mas essa água é do lago, o lago é deste ecossistema, este ecossistema é da natureza, a natureza é a nossa casa. A água não é só vossa, é de todos. E Vossa eqüinência e eu também somos parte da natureza, nossa mãe gentil. Pavio Curto bufa, dá coices:-A água é minha! -Vossa eqüinência tem escritura, contrato de locação, comodato, arrendamento? -Ah!, é assim? Pois se ergues da justiça a clava forte, verás que eu não fujo à luta! -Então é melhor vossa eqüinência reclamar para o juiz. Pavio Curto, sem muita paciência para o estudo, não era muito forte em ortografia. Vê um turista com uma camiseta escrito pineapple juice e pensa que é um juiz.. Vê o desenho de um abacaxi estampado e diz: - Juiz Abacaxi, tenho uma causa contra a anta. $O$ turista, que não entende português, acha que o cavalo está convidando-o para cavalgar. O turista monta. Cavaleiro e cavalo atacam a anta. Para o turista, a caça é só uma diversão. Ergue a clava forte e abate o tapir. Pavio Curto agradece a ajuda ao falso juiz. O turista (na língua dele): - Cavalinho, é muita hospitalidade me proporcionar tanto entretenimentol Como diz o povo; quem não tem cão, caça com gato; quem não tem moto, monta cavalo. Para demonstrar minha gratidão, vou te dar sela, estribo, arreio, freio e um nome; Rédea Curta. - Que anta que eu fuil - diz o cavalo- para cobrar uma pequena dívida, arranjei um grande prejuizo! De Pavio Curto acabei virando Rédea Curta e dei adeus à minha liberdade... 


\section{GRTOS, GEMIDOS Y ZUMBIDOS ${ }^{3}$}

Lectora, estimada amiga, que usas palabras extrañas como alimento para tu imaginación,

Este es Barranco, este es su «puentecito escondido entre follajes y añoranzas».

Este es el Puente de los Suspiros.

Este es el Museo de Arte.

Esta es la obra más famosa del piurano Luis Montero:

Losfunerales de Atabualpa.

¡Qué tela majestuosa!

¡Más de tres metros de altura, más de cuatro metros de ancho!

En el centro de la pintura,

Una mujer llora la muerte de Atahualpa.

Las mujeres son indias, pero aparecen como mujeres italianas vestidas con túnicas, con la piel blanca y el rostro con rasgos europeos. Las mujeres incas, en esta pintura, simbolizan el mito: las princesas son hijas del Sol.

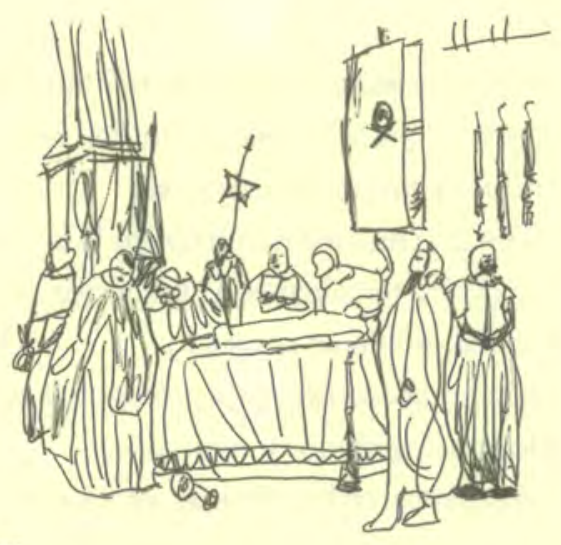

Atahualpa muere, Pizarro proclama, pero ¿solo él lleva

la fama?

- Cada cabeza, cada sentencia; su opinión, su verdad.

Venga más cerca, estimada compañera, lectora amiga.

¿Oyó un gemido?

- ¿Quién gime?

-Son las mujeres.

Ellas reclaman:

-Nosotras nos hacemos fuerza. ¿No eres tú quien gimes?

Presta atención: ¿oíste un zumbido?

- ¿Quién zumbe?

-Es un mosquito.

\footnotetext{
${ }^{3}$ BRADOS, GEMIDOS E ZUMBIDOS: Leitora, minha companheira, / que usa palavras alheias como alimento para sua imaginação, // Este é o Ipiranga, estas são as famosas «margens plácidas». / Este é o Parque da Independência. / Este é o Museu Paulista. / Esta é a obra mais famosa do paraibano Pedro Américo: / Independência ou Morte. / Qú tela majestosa! / Mais de quatro metros de altura, / mais de sete metros de comprimentol / No centro da pintura, / D. Pedro I solta «o
} 
Se posó en la oreja de una mujer y comienza a implicarse:

—QQué babosa! ¿Piensas solo que está «durmiendo eternamente el sueño eterno»? ¿No puedes quedarte quieta? ¡Sino te pico la oreja!

La mujer contesta:

- iNo me molestes, mosquito! Tus amenazas no me quietan ni me inquietan. Quien me «inquieta» es el virrey allá en frente. Yo voy con su ritmo. Es él quien me hace aquietar más calma o más triste, que me hace llorar o parar.

Parece que estoy oyendo el Virrey masticar:

-Y yo voy al ritmo de la Monarquía. Otros irán al ritmo de la República. Y otros, del Banco Mundial...

¿Cuál es la lección de la historia? No seré yo quien la enseñaré.

Apuesto que la lectora encontrará más de una lección.

Inclusive una que yo ni pensé.

Al final, la historia no fui yo que la inventó.

No quiero terminar con una lección.

Dejo aquí solo un zumbido.

La historia está hecha de protagonistas, antagonistas y figurantes.

De gritos, gemidos y zumbidos.

En la platea, en las tribunas, en los camarines, en el estadio,

todos oyen un grito de victoria.

Pero, estimada lectora amiga, parece que no son muchos los que consiguen oír una pluma, corriendo por el papel, en una mano femenina.

brado retumbantes. / Há pouco, leu cartas e documentos enviados do Rio. Entre eles, o decreto da Independência, assinado pela Imperatriz Leopoldina, soberana em exercício, durante a viagem do imperador. / -Então, Leopoldina assina, Pedro proclama, mas só o marido leva a fama? / —Cada cabeça, uma sentença; sua opinião, sua verdade. / Chegue mais perto, minha companheira, leitora amiga. / Ouve um gemido? / - Quem geme? / -É o eixo do carro de boi. /O bovino reclama: / -Nós é que fazemos força e você que geme? / Preste atenção: ouve um zumbido? / — Quem zumbe? / -É uma muriçoca. / Pousou na orelha do boi e começa a implicar: / - Sua lesma! Pensa que está «deitado eternamente em berço esplêndido»? Não dá pra ir mais depressa? Se não eu vou picar a sua orelha! / O bovino retruca: / -Não me amole, muriçoca! Suas ameaças não me comovem nem me movem. Quem me move é o boiadeiro lá na frente. Eu vou no seu ritmo. É ele quem me faz ir mais ligeiro ou mais devagar, que me faz andar ou parar. / Parece que estou ouvindo o boiadeiro ruminar: / —E eu vou no ritmo da monarquia. Outros irão no ritmo da república. E outros do FMI...// Qual a lição da história? Não sou eu quem vai ensinar. / Aposto que a leitora vai encontrar mais de uma lição. / Inclusive uma que eu nem pensei. / Afinal, a história não fui eu que inventei. / Não quero terminar com uma lição. / Deixo apenas um zumbido. / A história é feita de protagonistas, antagonistas e figurantes. / De brados, gemidos e zumbidos. / Na platéia, nas arquibancadas, nos camarotes, no sambódromo, / todos ouvem um brado retumbante. / Más, minha leitora amiga, parece que não são muitos os que conseguem ouvir uma pena, correndo pelo papel, em uma mão feminina. 


\section{HERCULES Y EI, CHRRO"}

Había un serrano

que siempre iba a buscar agua al dique.

Él cargaba latones de agua

con un carreta de bueyes.

Hércules era su nombre.

Un año, llovió mucho en febrero,

el camino se volvió barro

y su buey se tiró a la borda.

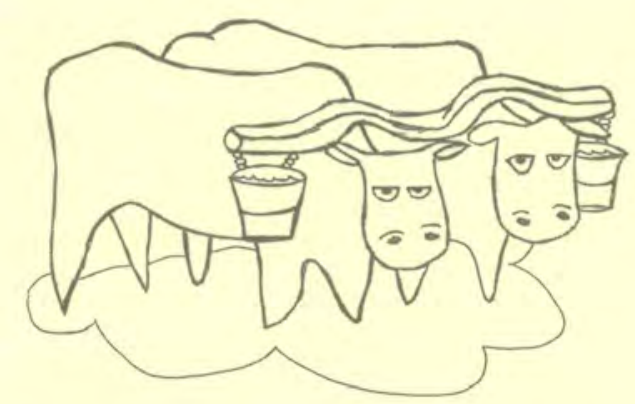

El serrano se sentó a la orilla del camino,

Alzó los brazos al cielo, suplicando:

— ¡Hércules, mi padrino, ayúdame tú!

El serrano esperó, paciente y esperanzado.

Cuando ya comenzaba a quedar impaciente, oyó:

-iPsiu!

Se volteó y no vio nada.

—P Psiu! —oyó de nuevo.

Prestando atención, percibió que la voz

no venía de fuera, venía de su cabeza.

\footnotetext{
${ }^{4}$ HÉRCULES E O CARRO: Havia um sertanejo / que sempre buscava água no açude. / Ele carregava latōes de água / com um carro de boi. / Hércules era seu nome. / Um ano, choveu muito em fevereiro, / a estrada virou brejo / e seu boi atolou. / O sertanejo sentou à beira da estrada, / ergueu os braços para o céu, suplicando: / - Hércules, meu padrinho, me acuda! / O sertanejo esperou, paciente e esperançoso. / Quando já começava a ficar impaciente, ouvių: / - Psiu! / Olhou em volta e nada viu. / -Psiu! —ouviu de novo. / Prestando atenção, percebeu que a voz / não vinhá de fora, vinha da sua mente. / Leia o que ele ouviu: / - Levante-se, homem! / Lembre-se da frase famosa de Euclides: / «o sertanejo é antes de
} 
Lea lo que él oyó:

— ¡Álzate, hombre!

Acuérdate de la frase famosa de Euclides:

«El serrano es, antes que nada, fuerte».

Mueve tus piernas, mueve tus brazos, usa la cabeza:

¡Ayúdate que el cielo te ayudará!

Hércules, el serrano, oyó esa voz

en su mente, agradeció al padrino

por su inspiración,

usó la cabeza, los brazos y las piernas

y desatolló su bueyecito.

tudo um forten. / Mexa as pernas, mexa os braços, use a cabeça: / ajuda-te, que o céu te ajudará! / Hércules, o sertanejo, ouviu aquela voz / na sua mente, agradeceu ao padrinho / pela sua inspiração, / usou a cabeça, os braços e as pernas / e desatolou o seu boizinho. 


\section{LA URRACA AZUL Y LA BANDA DE PAVOS"}

En los pinos del Marañón, una urraca azul

cantaba huainos y bailaba sayas.

Pero creía ser muy provinciana

y decidió globalizarse.

Tomó un avión para Nueva York

y fue a intentar la suerte en una banda de rock,

The Peacock Band.

Vistió la camisa de la banda, quiso intentar ser vocalista y arriesgó

The rainbow of my feathers, el mayor suceso de la banda.

No intentó más:

los gringos rasgaron su camisa y expulsaron a la caradura gritando todos ;Blue, go bome!

De regreso a los pinos del Marañón,

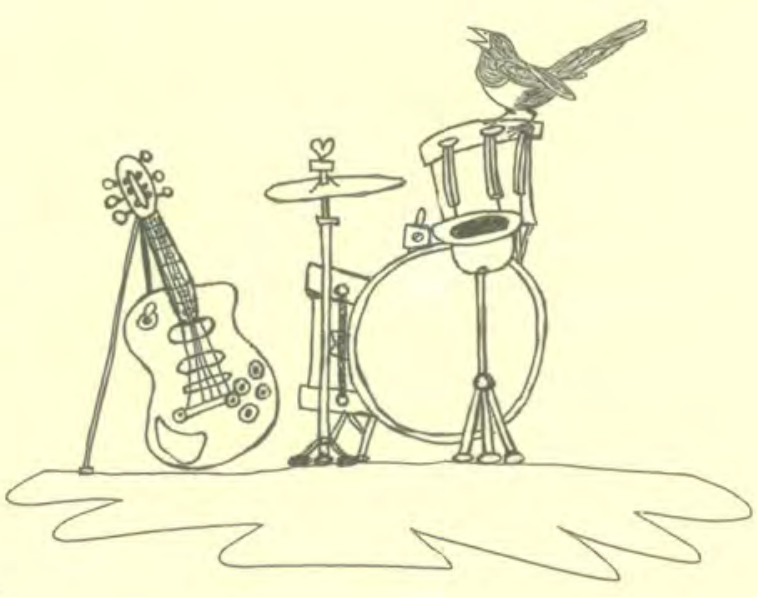
intentó volver al conjunto regional, pero le fue mal: dijeron que ella estaba americanizada y que cantaba con dejo.

\footnotetext{
‘ A GRALHA AZUL E O PAVÃO: Nos pinheirais do Paraná, / uma gralha azul / cantava guarânias e chorinhos. / Mas se achou muito periférica / e resolveu se globalizar. / Pegou um avião pra Nova York / e foi tentar a sorte em uma banda de rock, / The Peacock Band. / / Vestiu a camisa da banda, / quis dar uma de vocalista / e arriscou / The rainbonj of my feathers, / o maior sucesso da banda. // Não deu outra: / os gringos rasgaram sua camisa / e expulsaram a cara-de-pau / aos gritos de Blue, go! / / De volta aos pinheirais do Paraná, / tentou voltar ao conjunto regional, / mas se deu mal: / disseram que ela estava americanizada / e que cantava com sotaque. // A gralha azul ficou down / e buscou seu travesseiro cqnselheiro // No dia seguinte, declama: / «Now is the winter of our discontent / Made glorious summen) / e inventa a guarânia-rock / e o rockchorinho. // Não deu outra: / deu Emy...
} 
La urraca azul se quedó down

y buscó su almohada consejera.

Al día siguiente, declama:

«Now is the winter of our discontent

Made glorious summen)

$\mathrm{e}$ inventa un huaino-rock

y una saya-rock.

No se ganó con nada:

Se ganó el Emmy... 


\section{EL PAVO SE QUEJA CON JUNO}

El pavo, lo sabes, es el ave preferida de Juno. Fue esta diosa — cuenta Ovidio en las Metamorfosis que adornó su cola con los ojos del infeliz Argos, gigante con cien ojos, muerto a mano del astuto Mercurio, bajo comando de Júpiter. Pero esta es una larga historia...

Pues parece que un día el pavo se fue a quejarse con Juno. ¿Sabes por qué? Porque no tenía la voz de la cuculí, cuyo canto es objeto de encanto, poemas y canciones:

-No apenas abro el pico, todos se ríen...

La diosa intenta consolar a su protegido:

- $A$ Ah!, mi Pavo cristatus, pero tú vences en belleza: tu cuello es una columna de esmeraldas; tu cola, un abanico de piedras preciosas.

— ¡Oh, diosa!, ¿de qué me sirve una belleza muda?

Pobrecito, deja que canten otros varones más famosos.

Que canten Virgilios, Dantes, Vallejos, Chocanos, Borges, Eguren, Sologuren... La Naturaleza dio, a cada uno, ciertas dotes: a ti, la belleza; al gavilán, la fuerza; al ruiseñor, el canto; al cuervo, Poe; al cisne, Andersen; a la paloma, Yradier; a ti, Melgar. Y, a cada día, cada uno agradece por sus dotes. Por eso, no seas parvo, no te irrites, deja de envidiar las dotes de los demás. Abre los ojos, mira tu riqueza y no dejes que una envidia insensata

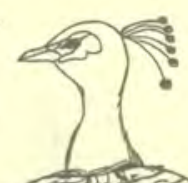
robe tu felicidad.

Pasó un ganso, que no formaba parte de la fábula, y se quedó con la pulga detrás de la oreja, y hasta hoy quiere dar picadas a quien se aproxima, pensando que es la Envidia Insensata que quiere robar su felicidad...

\footnotetext{
'OPAVÃOSEQUEIXA A JUNO: O pavão, você sabe, é a ave preferia de Juno. Foi essa deusa - conta Ovídio nas Metamorfosesque enfeitou a sua cauda com os olhos do infeliz Argus, gigante com cem olhos, morto pelo astuto Mercúrio, a mando de Júpiter. Mas essa é uma longa história... Pois não é que um dia o pavão foi se queixar a Juno? Sabe por quê?? Porque não tinha a voz do sabiá, cujo canto é objeto de encanto, poemas e canções:-Mal eu abro o bico, todos riem... A deusa procura consolar seu protegido: -Ah!, meu Pavo cristatus, mas você vence em beleza: seu pescoço é uma coluna de esmeraldas; sua cauda, um leque de pedras preciosas. - Ó deusa, de que me serve uma beleza muda? - Pobrezinho, deixe que cantem outros varões assinalados. Cantem Virgilios, Camòes, Cíceros, Ruis, Dias, Chicos, Patativas... A Natureza deu, a cada um, um certo dote: a você, a beleza; ao gavião, a força; ao sabiá, o canto; ao corvo, Poe; ao cisne, Andersen, à asa branca, Gonzaga; à você, Braga. E, a cada dia, cada um agradece o seu dote. Por isso, não seja parvo, não encrespe, deixe de olhogordo em cima dos dotes alheios. Abra olhos, veja sua riqueza e não deixe que uma inveja insensata roube sua felicidade. Passou um ganso, que não fazia parte da fábula, ficou com a pulga atrás da orelha, e até hoje quer dar bicadas em quem se aproxima, pensando que é a Inveja Insensata que quer roubar sua felicidade...
} 


\section{EL GAVILAN HERIDO POR UNA FLECHA ${ }^{x}$}

El indio tucán estira el arco y lanza la flecha.

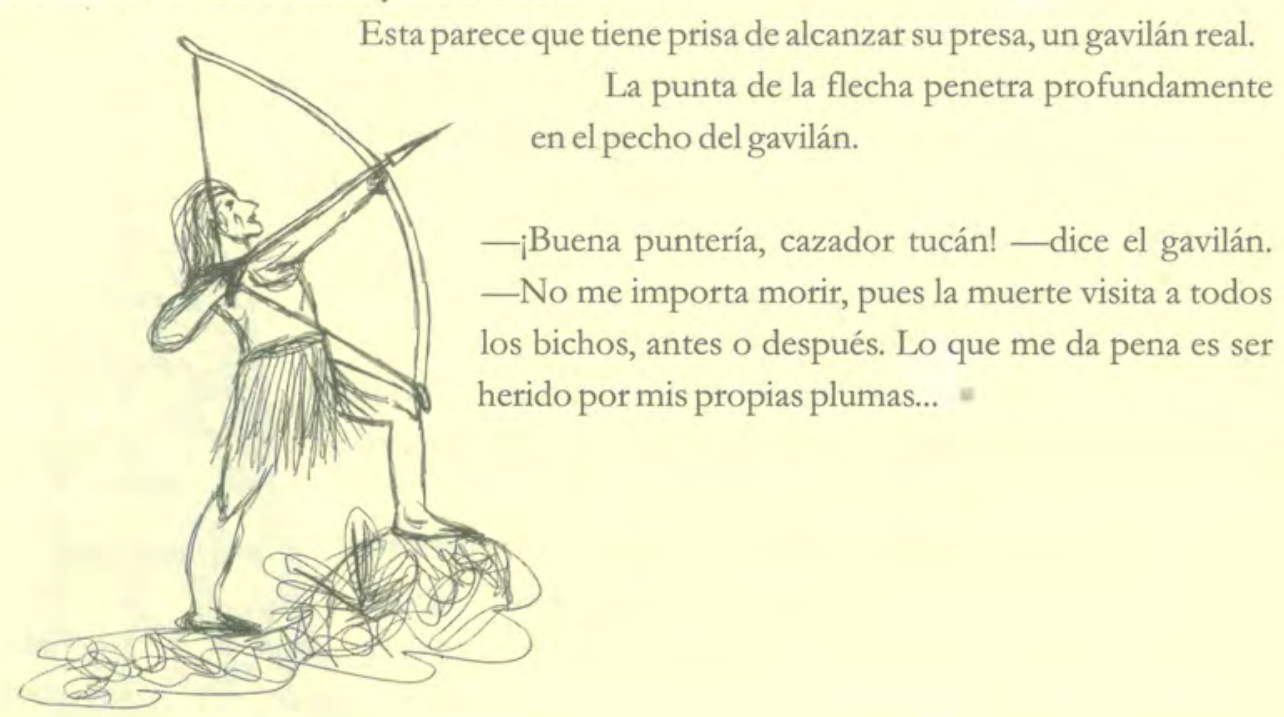

\footnotetext{
O GAVIÃO FERIDO POR UMA FLECHA: O índio tucano estica o arco e solta a flecha Ela parece que tem pressa de atingir sua presa, um gavião real. A ponta da flecha penetra profundamente no peito do gavião. - Bela pontaria, caçador tucano! — diz o gavião. — Eu não me importo em morrer, pois a morte visita todos os bichos, um dia ou outro. O que me entristece é ser ferido pelas minhas próprias penas...
} 